nation of deaths in the population under the age of 65 (by using husband's or father's occupation for analysis of women and children), though the longitudinal study has managed to extend analysis to older age groups ${ }^{10}$ and to cancer registration data ${ }^{11}$ and the general household survey annual report also provide analysis of health measures by socioeconomic group.

These difficulties have led to proposals for alternative measures of social stratification ${ }^{12}$ and to the adoption of an area based method of analysis. ${ }^{13}$ The near universal use of postcodes as a basis for area classification means that most events can be allocated geographically, thus overcoming many of the limitations described. In addition, compared with social class deprivation measures show distinct discrimination between populations. Classification of the population on the basis of the area in which it lives could therefore provide a valuable alternative strategy for analysis of data in relation to socioeconomic characteristics and enhance the possibilities of epidemiological examination of an extended range of routine health data for which social class is mostly not available. The continuous nature of a deprivation score also offers greater flexibility in analysis.

Debate about the ideal composition of a deprivation measure ${ }^{1+}$ is hardly likely to be resolved, though better measures of relative disadvantage could be constructed if government departments would make available at small area level some of the information on income (inland revenue) and supplementary benefits (social security) on the same basis as unemployment statistics. " Our own measure seems as robust as any other candidate in explaining variations in health (unpublished data); it correlates strongly not only with the standardised mortality ratio for ages $0-64(0.75)$ but also with the census measure of the percentage of the population (in private households) reporting themselves as unable to work due to permanent sickness
$(0 \cdot 77)$ and adheres to the concept of deprivation of material resources in a way that is not true for all such measures proposed. To promote its use on a consistent basis we suggest that the census output for 1991 should incorporate one or more similar measures; this would facilitate access to them and, by providing uniform measures, increase the comparability of data emerging from studies that use this approach in analysis.

This research was funded by the chief scientist, Scottish Home and Health Department. We thank the Office of Population Censuses and Surveys for use of published data, the registrar general, Scotland, for supplying census and mortality data, and Brian Jarman and Madhavi Bajekal for calculating the deprivation scores for wards of England and Wales.

1 Office of Population Censuses and Survers. Occupational mortality decennial supplement 1979-80, 1982-3. London: HMSO, 1986

2 Office of Population Censuses and Surveys and General Register Office Scotland. Census 1981, key statistics for urban areas. Scotland, England and Wales. London: HMSO, 1984.

3 Carstairs V, Morris R. Deprivation and mortality: an alternative to social class? Community Med 1989;11:210-9.

Office of Population Censuses and Survers. Mortalty statstess 1980-2. London: HMSO, 1983-4. Series DH1 Nos 9, 12, 13

Holterman S. Areas of deprivation in Great Britain: an analysis of 1971 census data. Social Trends 1975:6:33-47.

6 Townsend P Phillimore P Beatie A. Healsh and deprivation: inequality and the north. London: Croom Helm, 1988.

Townsend P, Davidson N, Whitehead M, Black D, eds. Inequalities in health the Black report and the health divide. Harmondsworth: Penguin, 1988

Jones IG, Cameron D. Social class analysis: an embarrassment to epidemiology. Community Med 1984;6:37-46.

Community Med 1984;6:37-46.
Stern J. Social mobility and the interpretation of social class mortality Stern J. Social mobility and the interpretation of
differentials. Fournal of Social Policy 1983;12:27-49.

10 Fox AJ, Goldbutt P. Socioeconomic differentials in mortality 1971-75. London: HMSO, 1982. (Office of Population Censuses and Surveys series LS1.

Leon D. Social distribution of cancer 1971-75. London: HMSO), 1988. (Office of Population Censuses and Survers Series LS3.

12 Goldthorpe J, Hope K. The social classification of occupations: a new approach and scale. Oxford: Clarendon Press, 1974.

13 Carstairs V. Small area analvsis and health service research. Community Med 1981;3:131-9

14 Townsend P. Deprivation. Fournal of Social Policy 1987;16:125-46.

15 Department of Environment. Unemployment statistics for small areas. Emplovment Gazette 1984;92:393-9.

Accepted 1 A ugust 1989
Medical Research Council

Environmental

Epidemiology Unit,

Southampton General

Hospital, Southampton

SO9 4XY

C A C Wickham, MSC,

statistician

K Walsh, MRCP,

epidemiologist

C Cooper, MRCP,

epidemiologist

D J P Barker, FRCP, director

B M Margetts, PHD,

nutritionist

$\mathrm{J}$ Morris, PHD, research

assistant

Department of Medicine for the Elderly, St Helen's

Hospital, Hastings, East Sussex

S A Bruce, MRCP, consultant geriatrician

Correspondence to:

Professor Barker.

Br 118.4.7 1989:299-889-92

\title{
245 Dietary calcium, physical activity, and risk of hip
} fracture: a prospective study /"

\author{
C A C Wickham, K Walsh, C Cooper, D J P Barker, B M Margetts, J Morris, S A Bruce
}

\section{$20 \overbrace{}^{\mathrm{A}}$}

Objective-To determine whether low dietary calcium intake and physical inactivity are risk factors for hip fracture among subjects aged 65 and over.

Design-Fifteen year follow up study of a large cohort of randomly selected elderly people living in the community, who had taken part in the 1973-4 survey of the Department of Health and Social Security, and for whom dietary and other data were recorded at initial interview and medical assessment.

Setting-Eight areas in Britain (England (five), Wales (one), and Scotland (two)).

Subjects - 1688 Subjects living in the community, of whom 1419 subjects ( 720 men and 699 women) agreed to participate. 1356 Subjects completed a seven day dietary record and 983 (542 men and 441 women) agreed to be assessed by a geriatrician.

Results - Incidence of hip fracture increased with age and was higher in women than men. Comparison with matched controls showed no evidence that the risk of hip fracture was related to calcium intake: the odds ratio for the lowest third of dietary calcium compared with the highest was 0.7 (95\% confidence interval 0.1 to 3.9) after adjustment for smoking and body mass index. The adjusted odds ratio for the lowest third of outdoor activity compared with the highest was $4.3(0.7$ to 26.8$)$, and that for grip strength was $3.9(0.7$ to $23 \cdot 0)$.

Conclusions-Reduced intake of dietary calcium does not seem to be a risk factor for hip fracture. Further evidence is provided that physical activity in the elderly protects against hip fracture.

\section{Introduction}

An important issue in public health is whether supplementation of calcium in the diet of elderly people will prevent osteoporosis and hip fracture. Evidence on the relation between calcium intake and risk of fracture from cross cultural and case-control comparisons is inconsistent..$^{2}$ In a recent case-control study in southern Britain there was no relation between calcium intake and hip fracture in women, but men with daily intakes above $1 \mathrm{~g}$ had lower risks. ${ }^{3}$

The only reported prospective study is a 14 year follow up study of 957 men and women living in an upper middle class white community in California, in which the risk of hip fracture was inversely related to dietary calcium. ${ }^{+}$From this it was concluded that the risk might be reduced by increasing consumption of 
dietary calcium above the current recommended daily allowance in the United States of $800 \mathrm{mg}$ a day for adults.

We report the results of a 15 year follow up study of a national sample of elderly men and women in Britain, for whom dietary and other information was recorded at an initial interview and medical examination, and among whom cases of hip fracture were subsequently identified. This is the first such prospective study in Britain.

\section{Subjects and methods}

During 1973-4 the Department of Health and Social Security surveyed random samples of people aged 65 and over in eight areas in Britain (five in England, one in Wales, and two in Scotland) to assess the nutritional state of the elderly population. The areas were chosen so that the socioeconomic characteristics of the study sample were representative of elderly people in Britain other than those living in institutions. As a basis for selecting the areas information on a range of socioeconomic variables was obtained from census data on local authorities throughout Britain. People in the eight areas chosen were randomly selected from family practitioner committee lists of all patients aged 65 and over. Stratified sampling was used to obtain equal numbers of men and women aged 65-74 and 75 and over.

Of 1775 people selected, 1688 were living in the community and were asked to take part in the study, and $1419(84 \%)$ of these ( 720 men and 699 women) agreed. A trained interviewer in each area inquired about accommodation, household amenities, and social activities. An outdoor activities index (scale 0-91) was derived from a series of questions mainly scoring the frequency and duration of spells spent in the open air. All except 63 subjects completed a seven day dietary record, from which the sizes of the portions were used to estimate weight of food consumed.

Nine hundred and eighty three people (542 men and 441 women) agreed to be examined by a geriatrician using a standardised procedure. This group contained more men than the group who did not agree to be examined $(55 \% v 41 \%)$, but their ages, index of outdoor activity, and intake of dietary calcium were similar. Examination included measurement of height, weight, and strength of grip with isometric dynamometry. Subjects were categorised by the geriatrician in terms of their mobility as housebound, with limited outdoor mobility, or with full outdoor mobility. Current smoking habits were recorded.

In 1987-8 we followed up the 1419 subjects in three ways. Firstly, we traced them through the National Health Service Central Register to determine whether they were still alive. Death certificates were obtained for all those who had died and were coded according to the ninth revision of the International Classification of Diseases. Any mention of code 820 was counted as a hip fracture. Secondly, for subjects who were still alive or had died within the past two years we sent a letter to their most recent general practitioner, asking whether they had sustained a hip fracture since 1973. Thirdly, we searched hospital records in all hospitals with an

TABLE I - Incidence of hip fracture by sex and age

\begin{tabular}{cccc}
\hline Age (years) & No of cases of fracture & Person years at risk & Incidence/10000 person years \\
\hline & & Men & \\
$65-74$ & 0 & 970 & 0 \\
$75-84$ & 5 & 1969 & 30 \\
$\geqslant 85$ & 5 & 546 & 92 \\
$65-74$ & 12 & 1142 & 44 \\
$75-84$ & 16 & 2396 & 50 \\
$\geqslant 85$ & & 847 & 189 \\
\hline
\end{tabular}

emergency orthopaedic service in the six survey areas in England and Wales. Records found for subjects were checked for evidence of admission with a hip fracture. In Scotland a different procedure was adopted; the Scottish Health Service provided a list of all patients discharged from hospital after a hip fracture between 1973 and 1987 , and this was used to identify subjects in the study who had sustained hip fractures.

Forty four subjects had fractured a hip since the survey in 1973-4. The incidence of hip fracture was calculated for each sex and age group with person years of follow up as the denominator. We attempted to find four controls for each case of hip fracture, matched for sex, age, and area of residence at the time of the survey. Controls were selected only if they were alive at the time when their matched case sustained a hip fracture. Of the 44 cases of hip fracture, 29 had four controls, five had three controls, five had two controls, and three had only one control; two cases were excluded because no control could be found. These were a man and a woman aged 90 and 97 respectively. In 25 of the 42 matched cases a medical examination had been performed at the 1973-4 survey. The differences between the cases and their controls were analysed with conditional logistic regression for matched sets. ${ }^{5}$

\section{Results}

Of the 1419 subjects who were interviewed, 1340 were traced and had remained in Britain and 319 were alive on 1 May 1988. Twenty seven of the 44 subjects who had fractured a hip were identified from hospital records alone, six by general practitioners alone, and three from death certificates alone; the remaining eight were identified from more than one source. No subject had more than one hip fracture. None of the cases or controls for whom a medical assessment was available were diagnosed as having dementia. Table I shows the incidence of hip fracture by age and sex; this was higher in women than men and increased with age.

The risk of fracture was strongly related to body mass index (weight $/$ height $^{2}$ ) and smoking, with a fivefold increase in risk among those in the lowest third of the body mass index distribution of cases and controls and a fivefold increase among smokers (table II). The odds ratios for calcium intake, physical activity, and strength of grip were therefore adjusted to allow for the possible confounding effect of body mass and smoking. Table II shows unadjusted and adjusted odds ratios within thirds of the distributions of the variables. Adjusted ratios could be calculated only for the subjects who were medically examined. The adjusted ratios for calcium intake and outdoor activity therefore had wider confidence intervals than the unadjusted ratios, which were based on all subjects. The odds ratios for men and women were combined because the small number of cases in men made estimates imprecise.

There was little difference in the odds ratios for fracture within each third of calcium intake, either for unadjusted or adjusted ratios. Among men, the unadjusted ratios were $0.5,0.8$, and 1.0 from the lowest to the highest third of intake, and among women they were $1 \cdot 0,0 \cdot 6$, and $1 \cdot 0$. The average calcium intake in men was $870 \mathrm{mg} /$ day (interquartile range $632-1075 \mathrm{mg} /$ day) and in women as $730 \mathrm{mg} /$ day (interquartile range $537-882 \mathrm{mg} /$ day). When dietary calcium was analysed allowing for total energy intake, there remained no difference in the risk of fracture in relation to calcium.

The risk increased significantly from subjects with full outdoor mobility to limited outdoor mobility, reaching $5 \cdot 2$ in subjects who were housebound $\left(\chi^{2}\right.$ for trend $=4 \cdot 4, p=0 \cdot 04)$. There was a similar, though reduced, trend in adjusted ratios. The risk also 


\begin{tabular}{|c|c|c|c|c|c|c|}
\hline & Men & Women & $\begin{array}{l}\text { Unadjusted } \\
\text { odds ratio }\end{array}$ & $95 \%$ Confidence interval & $\begin{array}{l}\text { Adjusted } \\
\text { odds ratio }\end{array}$ & $95 \%$ Confidence interval \\
\hline Dietary calcium (mg/day) & $\begin{array}{c}<694 \\
694- \\
\geqslant 999\end{array}$ & $\begin{array}{l}<588 \\
588 \\
\geqslant 802\end{array}$ & $\begin{array}{l}0.8 \\
0.6 \\
1.0\end{array}$ & $\begin{array}{ll}0.3 \text { to } & 2.0 \\
0.3 \text { to } & 1.5\end{array}$ & $\begin{array}{l}0 \cdot 7 \\
0 \cdot 9 \\
1 \cdot 0\end{array}$ & $\begin{array}{l}0 \cdot 1 \text { to } 3 \cdot 9 \\
0.2 \text { to } 4 \cdot 3\end{array}$ \\
\hline Mobility & $\left\{\begin{array}{l}\text { Housebound } \\
\text { Limited outdoor } \\
\text { Full outdoor }\end{array}\right.$ & & $\begin{array}{l}5 \cdot 2 \\
1.9 \\
1.0\end{array}$ & $\begin{array}{l}0.8 \text { to } 33.2 \\
0.3 \text { to } 10.8\end{array}$ & $\begin{array}{l}2 \cdot 2 \\
1.6 \\
1.0\end{array}$ & $\begin{array}{l}0.3 \text { to } 16 \cdot 1 \\
0.2 \text { to } 10.5\end{array}$ \\
\hline Outdoor activity index & $\begin{array}{l}<50 \\
\quad 50- \\
\geqslant 77\end{array}$ & $\begin{array}{l}<44 \\
44 \\
\geqslant 57\end{array}$ & $\begin{array}{l}3 \cdot 9 \\
3 \cdot 1 \\
1 \cdot 0\end{array}$ & $\begin{array}{l}1.4 \text { to } 10.9 \\
1.1 \text { to } 8.6\end{array}$ & $\begin{array}{l}4 \cdot 3 \\
4 \cdot 9 \\
1 \cdot 0\end{array}$ & $\begin{array}{l}0.7 \text { to } 26.8 \\
0.9 \text { to } 26.6\end{array}$ \\
\hline Strength of grip (kg) & $\begin{aligned} &<26 \\
& 26 \\
& \geqslant 31\end{aligned}$ & $\begin{aligned}< & 17 \\
& 17- \\
\geqslant & 20\end{aligned}$ & $\begin{array}{l}2 \cdot 3 \\
0 \cdot 5 \\
1 \cdot 0\end{array}$ & $\begin{array}{ll}0.6 \text { to } & 8.6 \\
0.1 \text { to } & 2.3\end{array}$ & $\begin{array}{l}3 \cdot 9 \\
0 \cdot 6 \\
1 \cdot 0\end{array}$ & $\begin{array}{l}0.7 \text { to } 23 \cdot 0 \\
0.1 \text { to } 3 \cdot 4\end{array}$ \\
\hline Body mass index $(\mathrm{kg} / \mathrm{m})$ & $\begin{array}{l}<23 \\
23- \\
\geqslant 26\end{array}$ & $\begin{array}{l}<23 \\
23- \\
\geqslant 27\end{array}$ & $\begin{array}{l}5 \cdot 4 \\
3 \cdot 2 \\
1 \cdot 0\end{array}$ & $\begin{array}{l}1.2 \text { to } 25 \cdot 7 \\
0.6 \text { to } 17 \cdot 0\end{array}$ & & \\
\hline $\begin{array}{l}\text { Smoker at time of } \\
\text { interview }\end{array}$ & $\left\{\begin{array}{l}\text { Yes } \\
\text { No }\end{array}\right.$ & & $\begin{array}{l}5 \cdot 6 \\
1 \cdot 0\end{array}$ & $1 \cdot 81017 \cdot 7$ & & \\
\hline
\end{tabular}

* Adjusted for body mass index and smoking.

increased significantly with decreased scores on the outdoor activity index ( $\chi^{2}$ for trend $=7 \cdot 2, p=0 \cdot 007$ ); the adjusted ratios were larger than the unadjusted ones.

Among subjects with strength of grip in the lower third the odds ratio was 2.3 , increasing to 3.9 after adjustment for body mass index and smoking; there was, however, no trend.

\section{Discussion}

This 15 year follow up study ${ }^{2}$ was based on a national sample of 1419 elderly men and women in Britain taking part in a study of the nutritional state of the elderly. As elderly people living in institutions were not sampled the most frail and disabled people are likely to have been excluded, and this may explain the absence of clinical dementia among the subjects. The incidence of hip fracture in men and women was similar to other reported incidences in Britain. ${ }^{6}$

We identified 44 cases of hip fracture in the 1419 men and women studied and found matched controls for 42 of them. Comparison of the cases and their controls gave no evidence that the risk of fracture increased with declining dietary calcium, for either absolute calcium intake or intake relative to total energy. The risks associated with dietary calcium were little changed after adjustment for body mass index and smoking, both strong risk factors for hip fracture. Two other known risk factors were not recorded in this study: we have no information about consumption of alcohol nor on use of postmenopausal oestrogens. Adjustment for smoking may have accounted for some of the possible confounding effect of alcohol; it seems unlikely that the remainder would be masking an association between risk of fracture and calcium intake. It is also unlikely that many of the elderly women in the study would have been prescribed oestrogens; in a recent case-control study of hip fractures in Southampton among women aged 50 and over only $3 \%$ of cases and $5 \%$ of controls had ever been prescribed oestrogens.

The only other published prospective study was of 957 men and women in California who took part in a survey of risk factors for ischaemic heart disease, in which dietary calcium was inversely related to risk of hip fracture. ${ }^{+}$The subjects were an unrepresentative sample drawn from an upper middle class white community and stratified to include all hyperlipidaemic subjects identified at an initial survey. Dietary calcium was estimated from 24 hour recall, a less accurate measure than a seven day record. ${ }^{*}$ Mean calcium intakes were around $100 \mathrm{mg} /$ day lower than in our survey. Thirty three of the subjects sustained hip fractures, and the incidence of fractures was similar in men and women, a surprising finding, which was attributed to the protective effect of oestrogen taken by many of the women.

Our finding that dietary calcium is unrelated to the risk of fracture is consistent with a recent dietary comparison of 300 patients with hip fractures and 600 community controls in Britain. ${ }^{3}$ In that study dietary calcium and risk of fracture were not related in women or men, except that among men in the highest fifth of intake (above $1041 \mathrm{mg}$ daily) the risk was reduced. Without other evidence this last finding is difficult to interpret. In a similar comparison among Chinese people in Hong Kong higher dietary calcium was associated with lower risk $^{4}$; average calcium intake $(171 \mathrm{mg} /$ person/day) was, however, much lower than that in Britain. It may be argued, therefore, that the discrepant results of the two prospective surveys reflect lower dietary calcium intakes in California. There is, however, a wide overlap in the distributions of dietary calcium recorded in California and in the two British surveys, and in Britain at no level of intake below $1 \mathrm{~g}$ was there a relation with risk of fracture. We therefore conclude that the findings in California provide insufficient evidence for recommending increased calcium intake in elderly people in Britain. Two caveats need to be stated: firstly, because of the small number of cases identified the power of our study is low; this is apparent from the wide confidence intervals around the odds ratios; and, secondly, a seven day dietary record might result in misclassification of a proportion of subjects when used as an estimate of long term calcium intake and might reduce the power of the study further.

The risk of hip fracture increased with decreasing mobility and outdoor activity and was higher in subjects with the weakest grip. Case-control studies in Britain ${ }^{3}$ and Hong Kong' similarly have shown a strong inverse relation between risk of fracture and physical activity. Physical activity and muscle strength may protect against hip fracture by preserving bone mass or reducing the risk and severity of falls. ${ }^{10} \mathrm{~A}$ relation between exercise and bone mass has been reported, ${ }^{11-13}$ and a relation between physical activity and reported falling was evident in the data obtained at the initial interview in the present survey. ${ }^{1+}$ We interpret our findings as further evidence that physical activity in the elderly protects against hip fracture.

We thank the DHSS for allowing us to use data from its survey in 1973-4, and the information and statistics division of the Common Services Agency for the Scottish Health Service for providing data on hospital patients in Scotland. The DHSS survey was coordinated by Professor A N ExtonSmith. KW is supported by Esso UK. 
Royal College of Physicians, Fractured neck of femur provention and munasement Report London: Roval College of Physicians, 1989.

2 Kanis JA, Passmore R. Calcium supplementation of the diet-II. Br Med 1989;298:205-8

3 Cooper C, Barker DJP, Wickham C. Physical activity, muscle strength, an calcium intake in fracture of the proximal femur in Britain. Br. Med 1988;297:14+3-6

4 Holbrook TL, Barrett-Connor E, Wingard DL. Dictary calcium and risk of hip fracture: $1+$ vear prospective population study. Lancet 1988;ii: 1046-9.

Breslow NE, Day NE. Conditional logistic regression for matched sets. In Breslow NE, Day NE, eds. Statistical methods in cancer research. Vol 1. The analvsis of case comtrol studies. Lvons: International Agency for Research on Cancer, 1980:248-79.

6 Evans JG, Prudham D, Wandless I. A prospective studv of fractured proximal femur: incidence and outcome. Public Health 1979;93:235-41

Baker MR. An incestigation into secular trends in the incidence of femoral neck fracture using Hospital Activity Analysis. Public Health 1980;94:368$7+$
8 Marr JW. Individual dietary surveys: purposes and methods, World Rev Nutr Diet 1971:13:105-64.

9 Lau EMC, Donnan S, Barker DJP, Cooper C. Physical activity and calcium intake in fracture of the proximal femur in Hong Kong. Br Med $\mathrm{f}$ $1988 ; 297: 1+41-3$

10 Boyce W J, Vessey MP. Habitual physical inertia and other factors in relation to fracture of proximal femur. Age Ageing 1988;17:319-27

11 Smith R. Exercise and osteoporosis. Br.Med 7 1985;290:1163-4.

12 Huddleston AL, Rockwell D, Kulund DN, Harrison B. Bone mass in lifetime tennis athletes. FAMA 1980;244:1107-9.

13 Chow R, Harrison JE, Notarius CE. Effect of two randomised exercise programmes on bone mass of healthy postmenopausal women. $\mathrm{Br} \mathrm{Med} \mathcal{f}$ 1987;295:1+41-4.

14 Wickham C, Cooper C, Margetts BM, Barker DJP. Muscle strength, activity, housing and the risk of falls in elderly people. Age Ageing 1989;18:47-51

Accepted 1 A ugust 1989

\title{
Improved prognosis since 1969 of myocardial infarction treated in a coronary care unit: lack of relation with changes in severity
}

\author{
John L Hopper, Bhupendra Pathik, David Hunt, William W C Chan
}

Abstract

Objective-To study changes from 1969 to 1983 in the prognosis of patients with acute myocardial infarction treated in a coronary care unit.

Design-Mortality follow up of all patients with definite acute myocardial infarction.

Setting-The coronary care unit of the Royal Melbourne Hospital, a tertiary referral centre.

Subjects - 4253 Patients (3366 men, 887 women) admitted from 1969 to 1983.

Main outcome measure-Mortality recorded at discharge from hospital and 12 months after admission.

Results-Details of clinical findings, history, electrocardiograms, arrhythmias, and radiological findings were recorded on admission. Mean ages were $\mathbf{6 3}$ for women and 57 for men, and women had haemodynamically more severe infarcts than men. In the later years patients were older and had less severe infarcts. Overall, hospital mortality in men was $16.7 \%$ in $1969-73$ and $8.5 \%$ in $1979-83$ and declined in all grades of the Norris and Killip infarct severity indices compared with a constant $19.2 \%$ in women. Even after adjustment for age and severity by logistic regression, hospital mortality fell in men by an average of $8 \%(95 \%$ confidence interval $4 \%$ to $11 \%)$ a year but remained constant in women. By 1983 male mortality was $60 \%$ that of women of similar age and comparable severity of infarction. Mortality of hospital survivors at 12 months declined by $7 \%(4 \%$ to $9 \%)$ a year in both sexes, even after adjustment for age and severity, with a male to female mortality ratio of about $0 \cdot 8$. New indices were derived to predict mortality in hospital and at 12 months.

Conclusion-The observed declines in mortality cannot be explained by changes in severity of infarction or in prognostic characteristics of patients.

Royal Melbourne Hospital, Department of Cardiology, Melbourne, Victoria 3050, Australia

Bhupendra Pathik, FRACP

visiting associate

David Hunt, FRACP,

director

William W C Chan, FRACP, cardiologist

Correspondence to: Dr Hunt.

Br.Med f 1989;299:892-6 however, that patients with acute myocardial infarction the at home had better survival than those admit to hospital. ${ }^{1314}$ Reservations have been expressed about the effectiveness of coronary care units, ${ }^{15}$ and some have suggested that the decline in mortality from acute myocardial infarction in the United States may have been due to a higher proportion of "milder" cases among patients admitted to these units. ${ }^{16} 17$

This study was undertaken to ascertain whether the prognosis of patients with acute myocardial infarction admitted to the coronary care unit at the Royal Melbourne Hospital had changed between 1969 and 1983 and, if so, whether this change could be explained by any changes in the age distribution of patients admitted or in the severity of their infarctions. A previous report from this unit showed a significant fall in mortality in patients with $\mathrm{Q}$ wave myocardial infarction in mild and severe categories between 1969 70 and 1974-75 but no change among patients with cardiogenic shock. ${ }^{18}$

\section{Methods}

The Royal Melbourne Hospital is a 620 bed tertiary referral hospital affiliated to the university. Patients with suspected or definite acute myocardial infarction are admitted to the coronary care unit irrespective of age, provided beds are available. The general function and policies of the unit have been reported. ${ }^{19}$ From 1969 patient data were recorded by medical staff on questionnaire forms. This study was confined to patients with definite acute myocardial infarction. ${ }^{2021}$ Characteristics recorded for each patient on admission included history; clinical, electrocardiographic, and radiological findings; and arrhythmias. Outcome was recorded later.

Patients were classified by severity according to the Killip classification': class I-no heart failure; class II - heart failure (appearance of third heart sound or presence of basal crepitations or pulmonary congestion on radiograph, or both); class III - severe heart failure (pulmonary oedema); and class IV - cardiogenic shock. The Norris index of severity was computed from age, heart size, radiological changes in lung fields, location of infarct, systolic blood pressure, and history of ischaemia. ${ }^{+}$

From 1969 to 1983,8135 patients were admitted to the coronary care unit, of whom $4340(53 \%)$ had definite acute myocardial infarction. For 4253 of these patients ( 3366 men, 887 women) we had data on mortality at discharge from hospital and at 12 months after admission, and they constitute the present study population.

\section{STATISTICAL METHODS}

A tendency for the mortality to change over the 